Revista lus et Praxis, Año 17, No 2, 2011, pp. 25 - 52

ISSN 0717 - 2877

Universidad de Talca - Facultad de Ciencias Jurídicas y Sociales

"Nueva perspectiva del sistema de Derecho

Continental en Colombia"

Betty Martínez Cárdenas

\title{
NUEVA PERSPECTIVA DEL SISTEMA DE DERECHO CONTINENTAL EN COLOMBIA***
}

\author{
A NEW PERSPECTIVE OF THE CONTINENTAL TRADITION INTO \\ COLOMBIAN LEGAL SYSTEM
}

Betty Martínez Cárdenas**

\begin{abstract}
RESUMEN
Con el desarrollo de la jurisprudencia constitucional a partir de 1991, una parte de la doctrina colombiana plantea la necesidad de cambiar la naturaleza del Sistema jurídico colombiano, tradicionalmente de estirpe continental, a otra "mixta", con el fin de establecer entre nosotros el "Nuevo derecho". ¿Es esta necesidad realmente cierta? El estudio de la naturaleza del derecho colombiano a través de la técnica del derecho comparado demuestra, por el contrario, que no es simplemente el rol que se le atribuye a la jurisprudencia el que puede per se cambiar la naturaleza del Sistema, ya que, primero, por sus orígenes y principios generales se confirma el carácter romano-germánico del Derecho colombiano, y, segundo, que dentro de este Sistema, el Continental, la jurisprudencia tiene un rol mucho más importante que crear el derecho: el interpretarlo y actualizarlo.
\end{abstract}

ABSTRACT

With the development of the constitutional case law from 1991, part of the Colombian doctrine sets out the necessity of changing the nature of the Colombian legal system, of continental tradition, to one of a "mixed" nature with the purpose of establishing among us the "new law". Is this necessity truly certain? The study of the nature of Colombian law through the comparative law technique shows, by contrary, that it is not simply the role that is granted to the case law that can change the nature of the system, since, first, through its origins and general principles, the civil law character of Colombian law is confirmed, and, second, within this system, the case law has a role much more important than just creating law: that of interpreting and updating it.

\footnotetext{
"Este trabajo es resultado de investigación del Proyecto "Actualidad del Sistema de Derecho Continental en Colombia", desarrollado desde 2009 por la Línea de Investigación en Derecho Civil del Grupo de Derecho Privado de la Facultad de Jurisprudencia de la Universidad del Rosario, Bogotá, Colombia. Trabajo recibido el 16 de julio y aprobado el 27 de septiembre de 2011.

** La autora agradece a los estudiantes Erika Díaz Silva y Oscar Eduardo Cote Rangel su colaboración en la elaboración de este artículo, en el marco de su trabajo de investigación dentro del Semillero de Obligaciones y la Línea de Derecho Civil adscrita al Grupo de Investigación en Derecho Privado de la Facultad de Jurisprudencia de la Universidad del Rosario, Bogotá, Colombia.

*** Profesora Investigadora de Derecho Civil en la Facultad de Jurisprudencia de la Universidad del Rosario, Bogotá, Colombia. Correo electrónico: betty.martinez@urosario.edu.co.
} 


\author{
PALABRAS CLAVE \\ Derecho Civil, Nuevo Derecho, Sistema Continental \\ Key words \\ Civil Law, "New Law", Continental Tradition
}

\title{
I. INTRODUCCIÓN
}

"Si uno se ve a sí mismo dedicado a la reforma o a la revolución, los primeros pasos a seguir son los de la propia educación y la de los demás".1

La expresión "Sistemas de derecho" se debe al Profesor francés René David, quien la elaboró con el fin de comparar los derechos entre distintos Estados. Consciente de que el número de Derechos existentes en el mundo era infinito, observó sin embargo este Profesor, que muchos de ellos podían ser reagrupados de acuerdo con criterios tales como la técnica legislativa empleada, la manera de clasificar las reglas y los modos de razonamiento empleados por los intérpretes. A cada grupo encontrado dio, en principio, el nombre de "Familias de derecho", tal y como podría hacerse en otras ciencias, sin tener en cuenta las diferencias secundarias entre ellas, como de religión, lengua o raza. La clasificación en "Familias de derecho", en palabras del propio Profesor David, "reduce a cierto número de tipos la presentación y la comprensión del derecho en el mundo contemporáneo" 2 . Pero, posteriormente, el mismo Profesor cambió esta denominación por otra más amplia: "Sistema de derecho".

Un Sistema de derecho, en consecuencia, denota que a pesar de la pluralidad de Derechos, comparados los unos con los otros, se deduce de ellos la existencia de un vocabulario común, de grupos de normas que conciernen ciertas categorías, la utilización de ciertas técnicas para formular dichas reglas y ciertos métodos para interpretarlas, lo cual determina el modo de aplicar estas reglas y la función misma del Derecho ${ }^{3}$.

En la actualidad existen seis sistemas de derecho: Sistema de derecho continental, conocido también como "Romano-germánico"; la Common law; los antiguos derechos socialistas; los Sistemas religiosos; los Sistemas de Japón y de China, y los Sistemas relativos a los derechos africanos.

${ }^{1}$ Chomskr, Noam, La quinta libertad, La Intervención de los Estados Unidos en América Central y la lucha por la paz, Traducción de Castells, Carme, Editorial Crítica, colección Biblioteca de Bolsillo, Barcelona, 2003, p. 397.

2 David, René; Jauffret-Spinosı, Camille, Les grands systèmes du droit contemporain, 11 ème édition, Dalloz, Paris, 2002, № 16, p. 15.

${ }^{3}$ DAVID, JAUfFRet-SPINOSI, Les grands, cit. nota n. 2, p. 14. 
Los países que hacen parte de la Common law son Inglaterra, Irlanda, Gales, y las colonias del Reino Unido, los Estados Unidos, con excepción del Estado de Luisiana que se inscribe dentro de la tradición continental; Canadá, con excepción de Quebec, que también forma parte del Sistema continental; India, Malasia, Singapur, Australia, Nueva Zelanda y Sudáfrica. Debido a que Inglaterra no fue influenciada por esta recepción tardía de la cultura jurídica romana que se vivió en el continente europeo durante la Edad Media, ya que desde fines del siglo XIII se aplicaba un sistema de derecho creado por los nativos de la isla, cuyos métodos, paradójicamente, se parecían más a los del Derecho romano clásico ${ }^{4}$ y se apartaban completamente de los desarrollados en el continente. La regla de derecho en este Sistema, es aquella que busca solucionar un problema particular, y no formular una regla de conducta abstracta y general para el futuro; está ligada al monarca y al feudalismo. En efecto, el sistema anglo-americano de derecho comenzó en 1066, cuando Guillermo el Conquistador (William I) ganó contra los anglo-sajones la bataIla de Hastings y, a partir de allí, dominó gradualmente el resto del territorio de las Islas Británicas 5 . A este derecho se le dio por nombre "Common law", porque las Cortes Reales debían imponer un derecho común en toda Inglaterra. Las diferencias entre uno y otro sistema son notables en muchas de las instituciones jurídicas, tanto por la manera como han sido construidas, como por la manera como son aplicadas. Una clara ilustración de estas diferencias será tratada más adelante.

En cuanto al Sistema de derecho de los antiguos países comunistas, este era el aplicado por la Unión Soviética, a partir de la doctrina marxista-leninista, sobre cuyo fundamento se intentó crear en estos países una sociedad comunista, en la que no existiera ni Estado ni Derecho. Esto no fue logrado en ninguno de estos países, pero determinó que la forma de Estado "socialista" se diferenciara mucho del Estado "burgués" existente en los países cuya economía era de mercado. La desaparición en aquéllos de las clases sociales y la colectivización completa de bienes de producción marcaron las grandes diferencias de este sistema frente a los demás, sobre todo en relación con las nociones de propiedad y de contrato. Sin embargo, todos los países que formaban parte de la Unión Soviética o URSS tienen un Código Civil, fundado en los Principios de la legislación civil federal publicados en 1961, pero en ellos se separa el derecho civil del derecho de familia, lo cual justificó la promulgación de otros códigos en 1968. Sin embargo, en 1989, con el

\footnotetext{
${ }^{4}$ Peter, H., "Actio y writ" (1957), citado por Kunkel, Wolfgang, Historia del Derecho Romano, Ariel Derecho, Madrid, 1996 p. 193.

${ }^{5}$ ZweIGeRT, Konrad; KÖtz, Hein, An Introduction to Comparative Law, Vol. I., North-Holland Publishig company, Great Britain, 1977, p. 191.
} 
regreso de la Unión Soviética a la economía de mercado, la reunificación de Alemania, la división de Checoslovaquia en la República Checa y Eslovaquia; la desmembración de la antigua Yugoslavia, se han reformado todos los regímenes de propiedad de estos países para crear, en lugar del régimen socialista, regímenes de propiedad mixtos $^{6}$.

A los sistemas religiosos hacen parte, de otro lado, los países cuyos ciudadanos regulan sus relaciones basados en la religión. En los países cuya fe es musulmana, por ejemplo, la función legislativa está reservada a Mahoma. En efecto, toda vez que fuera a este profeta a quien se reveló la palabra divina (el Corán), él fue el único calificado para interpretar la revelación ${ }^{7}$ Luego de Mahoma, sus acompañantes (ashab) desarrollaron esos comentarios, pero como esta generación desapareció, las dos generaciones siguientes se transmitieron oralmente la tradición del Profeta en una serie de pasajes sucesivos (hadith), celosamente conservados por la memoria de los fieles. El conjunto de estos recitales está representado por la Sunna. Ellos complementan al Corán y lo explican. La Sunna y el Corán forman la Sharia (Šaría), esto es, la Vía, la Ley Divina ${ }^{8}$. Los países que pertenecen a este sistema son Arabia Saudita, Kuwait, Tchad, Mauritania, Sudán, Kuwait, Egipto, Afganistán, Iraq, Irán, Pakistán, Emiratos Árabes Unidos, Siria, Libia, Túnez, Marruecos, Indonesia, India, entre otros.

Japón y China, por el contrario, en sus instituciones jurídicas se acercan en gran medida a la tradición romano-germánica, sin perder por ello los caracteres especiales que le confiere a su sistema una larga tradición filosófica y cultural. Según ésta, todo hombre civilizado debe ser consciente de sus deberes ante la sociedad, razón por la cual debe ser preferida la conciliación o la mediación de los conflictos al ejercicio de acciones judiciales que tengan por objeto coaccionar a un individuo 9 . Ahora bien, sólo para los casos extremos y, en particular, para relacionarse con Occidente, ambos países elaboraron, en principio, Códigos civiles y penales, al estilo del Código Napoleónico de $1804^{10}$, con este propósito, una comisión especial fue otorgada al Profesor francés Gustave Emile Boissonade de Fontarabie, para hacer el proyecto de Código Civil y de

\footnotetext{
${ }^{6}$ Terré, Francois, Introduction générale au droit, 8e édition, Dalloz, Paris, 2010, № 62, p. 56.

${ }^{7}$ Losano, Mario G., Los Grandes Sistemas Jurídicos, Introducción al Derecho Europeo y Extranjero, versión castellana de Ruiz Miguel, Alfonso, Editorial Debate S.A., Madrid, 1993, p. 229.

${ }^{8}$ Mııııot, Louis Et Blanc François-Paul, Introduction à l'étude du droit musulman, Dalloz, Paris, 2001, p. 6. Losano, Los grandes, cit. nota n. 7, pp. 232 y ss.

${ }^{9}$ Losano, Los grandes, cit. nota n. 7, pp. 280 y ss.

${ }^{10}$ Un hermoso busto de este profesor recuerda este episodio del reinado del Derecho Francés al pie de la célebre Escalera M de la antigua Facultad de Derecho de la Universidad de París, en frente del Panteón.
} 
Código Penal de Japón durante el periodo de Meiji, para lo cual residió en este país desde 1873 hasta 1895; y otra, al jurista francés Jean Escarra, encargado de elaborar el Código Civil chino de 1929. Posteriormente, ambos sistemas cambiaron sus códigos para adoptar el BGB de 1896, por considerarlo más cercano a la tradición de sus pueblos. La revolución comunista en China, sin embargo, dejó sin vigor este último Código desde 1949 hasta 1978, época en la que la búsqueda de un acercamiento a la economía de mercado de Occidente la obligó a elaborar nuevas leyes en derecho de contratos (1999) y un proyecto de Código Civil en $2002^{11}$.

Finalmente, los países africanos, con excepción de aquellos cuya fe es musulmana o que hacían parte de las antiguas colonias inglesas, como Sudáfrica, utilizan a la costumbre como principal fuente de derecho ${ }^{12}$. En este grupo suele incluirse a Madagascar, que a pesar de no hacer parte del continente, comparte con él sus raíces étnicas y culturales ${ }^{13}$.

De esta manera, en Derecho comparado, los Sistemas de derecho ayudan a desarrollar investigaciones históricas o filosóficas del derecho; mejorar el conocimiento del derecho nacional, y, en materia internacional, los Sistemas son útiles para comprender mejor los pueblos extranjeros y aplicar un régimen adecuado en las relaciones entre Estados, y es una noción indispensable para toda tentativa de unificación del derecho ${ }^{14}$.

Colombia tradicionalmente ha hecho parte del Sistema continental, tal y como sucede con todos los países cuyas ciencias jurídicas están formadas sobre la base del Derecho romano. Ahora bien, durante los últimos años, cierta parte de la doctrina colombiana discute la pertenencia del Régimen colombiano a dicho Sistema, así como la subsistencia del mismo ${ }^{15}$ en razón al poder creador de derecho que parece atribuírsele cada día con más fuerza a los jueces, en particular a la Corte Constitucional.

La tendencia hacia una "emancipación de la tradición jurídica nacional"16 ha sido defendida sobre la base de incorporar la regla del "precedente juris-

\footnotetext{
${ }^{11}$ TeRré, Introduction, cit. nota n. 6 ( ${ }^{\circ}$ 5), p. 58.

${ }^{12}$ Losano, Los grandes, cit. nota n. 7, p. 193.

${ }^{13}$ TerRé, Introduction, cit. nota n. 6 ( $\mathrm{N}^{\circ}$ 5), p. 59.

${ }_{14}$ Para profundizar sobre este punto, ver: WATSON, Alan, Legal Transplants, an approach to comparative law. Second edition, The University of Georgia Press, Athens and London, 1993, pp. 1 y ss.

15 Se trata de las tendencias de "descodificación" y "constitucionalización" que parecen ser irreversibles en los países de tradición continental, y en particular en Colombia, como consecuencia del uso cada día más frecuente de la "acción de tutela". Al respecto ver MerRrman, John Henry; Pérez-Perdomo, Rogelio, The Civil Law Tradition, An Introduction to the Legal Systems of Europe and Latin America, third edition, Stanford University Press, Stanford, California, 2007, pp. 153 y ss.

${ }^{16}$ López Medina, Diego Eduardo, El Derecho de los Jueces, Segunda edición, Universidad de los Andes y Legis, Bogotá, 2008, p. 339.
} 
prudencial" como el camino hacia el establecimiento del "nuevo derecho" en Colombia ${ }^{17}$, esto es, de un sistema que prefiera "la adopción de estándares $O$ principios que, enunciando una regla generalísima, dejan su adecuación concreta a un juicio prudencial del intérprete y no a la capacidad de previsión del legislador"18. Sin embargo, ¿es exacto afirmar que la utilización de la técnica del "precedente jurisprudencial" cambia per se la naturaleza del Derecho colombiano? O mejor aún, ¿el Derecho colombiano, aun en su concepción continental tradicional, es realmente estático?

Para poder responder a estas interrogantes, es imprescindible conocer mejor el Derecho colombiano, y el propósito de este artículo es justamente contribuir a dicho conocimiento. Para ello, se utilizará la técnica del Derecho comparado para deducir en el Derecho colombiano la existencia de un vocabulario común, de grupos de normas que llevan a establecer sus categorías, la utilización de la técnica para formular dichas regla y los métodos de interpretación empleados. El campo de investigación ha sido restringido al Derecho Civil, por ser la rama de derecho que más ha conservado una concepción "tradicional" de la regla jurídica. El método de investigación aplicado es el sistémico, razón por la cual se confirmará que los componentes del Sistema colombiano comparten la naturaleza romano-germánica de todos los países que hacen parte del Sistema continental (I) y que, a pesar de la críticas, estos componentes no necesitan de transformación alguna hacia un "nuevo derecho", ya que son en sí mismos dinámicos (II).

II. Naturaleza romana de las instituciones juRídicas del SISTEMA CONTINENTAL, Y DEL DeRECHO COLOMBIANO EN PARTICULAR

Los orígenes del Sistema continental se remontan al siglo XIX, época en la que el objetivo del Derecho no podía ser otro que el de regular las relaciones entre los ciudadanos; razón por la cual, el eje de este Sistema es el Código civil. Las demás ramas del derecho, sistematizadas en otros códigos, fueron creadas con posterioridad, pero siguiendo siempre el sistema de aquel primer código. En consecuencia, esta naturaleza se desprende de la manera misma como los Estados pertenecientes a este sistema de derecho crearon sus reglas de derecho. Veremos así que la especificidad de estas normas se encuentra en sus raíces romanas, las cuales se transmitieron a Europa y Latinoamérica a través de dos acontecimientos: la formación de la universidad (A) y la codificación (B).

${ }^{17}$ LóPEZ, El Derecho, cit. nota n. 16, p. 323 y ss.

${ }^{18}$ LÓPEZ, El Derecho, cit. nota n. 16, p. 324. 


\section{1. la formación de las universidades y las raíces romanas de las normas de derecho aplicables en la actualidad}

Después de la caída del Imperio Romano de Occidente, en el año 476 d.C., el Derecho Romano también cayó y quedó en la oscuridad. En Oriente, sin embargo, la tradición romana se aplicó sin interrupción hasta la llegada de Justiniano, quien con sus Novelas y el abandono de la lengua latina por la griega, la ayudó a fundar, indirectamente, el Imperio Bizantino. No obstante, preocupado porque la ley no podría ser aplicada sino por los jueces y abogados que la hubieran aprendido en las Escuelas de Derecho, y consciente de la carencia de juristas en su imperio, Justiniano compiló seis siglos de cultura jurídica romana en el Corpus luris, haciendo de éste un "derecho popular" y la base del estudio del Derecho en dichas escuelas, pese a que, seguramente, iba a surgir otro problema adicional, como el de las traducciones falsas del Digesto al griego, que incluían comentarios del Anónimo y que crearon a la larga un nuevo código: los Basílicos y los Escolios a los Basílicos.

En Occidente, el Digesto estuvo perdido durante algunos siglos, hasta que a fines del siglo XII fue redescubierto por el boloñés Irnerio ${ }^{19}$. Este suceso marcó para este hemisferio el comienzo de las universidades ${ }^{20}$. En efecto, el Digesto "supuso el don del vigor y grandeza de la jurisprudencia romana"21, y con su estudio comenzó la evolución de la Escuela de Bolonia, primera universidad del continente ${ }^{22}$. Estos estudios del Digesto se hicieron mediante el empleo del método exegético, propio de los profesores bizantinos, así, el Corpus luris se explicaba "título por título y frase por frase" 23 . Las aclaraciones, por su parte, se hacían a través de "la glosa" (glosa interlineal o glosa marginal), que con el tiempo, formaron otro cuerpo anexo al Digesto ${ }^{24}$ del que podían surgir algunas "contradicciones", que para entonces se resolvían volviendo al texto original,

\footnotetext{
${ }^{19}$ KUNKEL, Historia, cit. nota n. 4 (N³), p. 184.

20 Época en la que surge la palabra "Universitas": Beuchot, Mauricio, El Espíritu filosófico medieval,

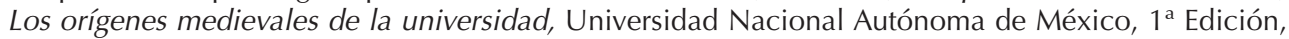
Ciudad Universitaria, México D.F., 1994, pp. 181 y ss,

${ }^{21}$ Kunkel, Historia, cit. nota n. 4 (N³), p. 189.

22 Al lado de la escuela de Bolonia, surgen también la escuela de teología de París, la cual nació con el privilegio del rey Felipe Augusto en 1200, la Universidad de Nápoles en 1224; la de Toulouse, en 1229; la de Salamanca en 1218 ó 1219. Oxford, por su parte, remonta sus orígenes a 1163, aunque sus estatutos datan de 1214, y los de Cambridge de 1236 y 1254 . Al respecto, véase: SaranYana, José Ignacio, Historia de la Filosofía Medieval, Colección Libros de Iniciación Filosófica, Editorial EUNSA, Segunda Edición Pamplona, España, 1989. p. 191.

${ }^{23}$ KUNKEL, Historia, cit. nota n. 4 (N³), p. 190.

${ }^{24}$ Es el caso de la "Glossa Ordinaria", del profesor boloñés de Derecho Arcusio, consistente en la recolección del primer cuerpo de glosas tendiente a profundizar y explicar los textos del Digesto.
} 
sagrado para los intérpretes ${ }^{25}$. La influencia del estudio del Digesto se extendió por toda Europa a través de las universidades ${ }^{26}$, lo cual llevó a la creación, hacia el siglo $\mathrm{XV}$, de una base común de cultura jurídica en Europa que confluyó a finales del siglo XVII con la filosofía racionalista que antecedió la Revolución Francesa y la ideología de la codificación.

Ahora bien, ¿cómo es que Colombia, que se encuentra al otro lado del Atlántico, pudo compartir este mismo lecho histórico de formación de su derecho? La respuesta se encuentra en la época de la Colonia. En efecto, durante la Colonia, el que ahora corresponde al territorio colombiano, se regía por el derecho español y las leyes especiales dadas para las Indias, como las Siete Partidas ${ }^{27}$. Ahora bien, las Siete Partidas son el último paso en la evolución del Derecho Español desde que el Imperio Romano fuera invadido por los bárbaros. En efecto, luego de esta invasión las leyes de Eurico $^{28}$, Alarico ${ }^{29}$ y demás reyes visigodos, fueron recopiladas en un código conocido como Liberjudicium o Forumjudicium, traducido al castellano como Fuero de los Jueces o el Fuero Juzgo. La característica de este código fue la de sistematizar principios de la legislación romana. Este Fuero rigió en el campo del derecho privado desde el tiempo de Rescesvindo ${ }^{30}$ hasta el tiempo de Pelayo, cuando por razón de la reconquista de los territorios ocupados por los moros fue necesaria la concesión a cada villa de hacer sus fueros particulares, hasta que España completó su unidad política. Lograda ésta, bajo el ánimo de hacer una legislación general, se expidió en el siglo X el Fuero Viejo de Castilla, que tuvo que ser corregido por el Rey don Alfonso el Sabio debido a que la antigua concesión de los fueros particulares terminó por darle un gran poder creador de derecho a las costumbres, que terminaron creando un sistema anárquico de aplicación de las leyes. Conocido como el Fuero Real, Fuero de las Leyes o Fuero de los Consejos de Castilla, fue el código utilizado para dotar de armonía la legislación española, pero sin gran éxito, ya que sólo rigió en algunas provincias, en tanto que las otras

\footnotetext{
${ }^{25}$ Otros métodos de interpretación lógica fueron creados, mediante la interpretación "limitativa y extensiva" que no podían ser recogidos por las resumidas glosas, por ello, éstas no fueron bien recibidas por todos los juristas posteriores, por ser éstas consideradas falsas o inexactas; pero, en la actualidad, de estas glosas se han derivado grandes principios del Derecho Internacional Privado y el Derecho Mercantil.

${ }^{26}$ En principio, esta enseñanza revistió un marcado carácter teológico que después llevó al estudio del Derecho Canónico.

${ }^{27}$ Mayorga García, Fernando, Estudios de Derecho Indiano. Colección Textos de Jurisprudencia, Centro Editorial Universidad del Rosario, Bogotá, 2003, pp. 133 y ss.

28 Año 476.

29 Año 506.

${ }^{30}$ Lex Wisigothorum de Rescesvindo (653-672).
} 
continuaron con el Fuero Viejo de Castilla ${ }^{31}$. En consecuencia, don Alfonso el Sabio hizo una nueva recopilación de leyes, bajo un plan metódico, a la que dio por nombre Las Siete Partidas. En esta recopilación "quedaron reunidos los principios de Derecho romano, los usos y costumbres de la época en que se expidió, las decisiones de los canonistas y las sentencias de los sabios y filósofos" ${ }^{\prime 2}$. Posteriormente, en el siglo XVI el Rey Felipe II hizo la Nueva Recopilación en nueve libros, divididos en títulos y éstos en leyes. Años más tarde, en 1805 fue promulgada la Novísima Recopilación de las Leyes de España, que aumentaba y corregía la anterior, pero que no alcanzó a regir en las colonias como consecuencia de las distintas guerras de independencia que se llevaron a cabo. Finalmente, las Leyes de Indias eran las especiales dadas por el Gobierno español para que rigieran en las colonias de ultramar. Recopiladas por Carlos II, se encontraban distribuidas en nueve libros, divididos en títulos y éstos en leyes ${ }^{33}$.

Luego de la guerra de Independencia, la Constitución colombiana de 1821 dispuso que siguiera rigiendo en el territorio nacional la legislación española que no fuera contraria a aquélla, así como las leyes y decretos que expidiera el Congreso. Estas leyes sólo dejaron de regir con las leyes del 13 de mayo de 1825, del 14 de mayo de 1834 y de 29 de junio de 1858.

Ahora bien, la historia de la recepción del derecho romano en Colombia habría podido detenerse en este punto, sin embargo, con la reconstitución de la República en forma unitaria en $1886^{34}$, y la expedición de los Códigos Civil y de Comercio que fundan sus disposiciones en principios derivados del derecho romano, estos principios siguen siendo aplicados desde entonces y sin interrupción hasta nuestros días.

La segunda razón que explica la aparición de estos Códigos en América Latina se encuentra en el desarrollo de un movimiento ideológico en el continente europeo: La codificación.

\footnotetext{
${ }^{31}$ Rodríguez Piñeres, Eduardo, Curso Elemental de Derecho Civil Colombiano, Tomo I, $2^{\circ}$ Edición, Librería Americana, Bogotá, 1923, p. 36.

32 Rodríguez, Curso, cit. nota. n. 31 ( $\mathrm{N}^{\circ} 21$ ), p. 37.

${ }^{33}$ En este mismo sentido, ver Ost CAPDequi, José María, Manual de Historia de Derecho Español en las Indias, y del Derecho propiamente indiano, Editorial Losada S.A., Buenos Aires, 1945, p. 62.

${ }^{34}$ Es particularmente importante la expedición el 21 de junio de 1887 de la Ley 57 de ese mismo año, con la cual se adoptaron los Códigos de la Nación, con el fin de unificar su legislación. Los Códigos adoptados por esta ley fueron el Civil, que había sido expedido en el año 1873 para los asuntos de competencia de la Unión, el cual era copia del Chileno redactado por Don Andrés Bello, y el de Comercio del extinguido Estado de Panamá.
} 


\section{La codificación}

El criterio predominante para la elaboración de los Códigos modernos fue la recopilación del derecho vigente, con las modificaciones y correcciones, que por política legislativa, fueran necesarias ${ }^{35}$. La idea de desarrollar un derecho autóctono fue rechazada por carecer de fundamentos lógicos. Para Savigny, por ejemplo, el Derecho, como la religión y la literatura, no son privativos de cada pueblo: "Se ha indicado anteriormente que en nuestra ciencia todo el éxito descansa en la posesión de los principios rectores; pues bien: esta posesión es justamente la base de la talla de los juristas romanos. Los conceptos y preceptos de su ciencia no son para ellos un producto de su arbitrio, son entes reales, cuya existencia y cuya genealogía han llegado a conocer a través de un trato íntimo prolongado". ${ }^{36}$

Los orígenes de la codificación se remontan a Francia, luego de la desaparición de la monarquía. Durante esta época surgió la era del estatismo y, en consecuencia, una "nueva" legislación debía tener por objeto la glorificación del estado nacional ${ }^{37}$ y obedecer al imperativo de unificación y centralización del territorio. El exagerado racionalismo de la época creó la necesidad de establecer un sistema legal que sustituyera al anterior y que se aplicara por igual a todos los franceses: El Código Napoleón (1); un sistema que respondiera al espíritu del pueblo: el BGB (2), y a la liberación de las Colonias de España: El Código de Bello (3).

1. El Código Napoleón. Luego de que la constitución fuera adoptada por Napoleón, éste creó una comisión de sólo cuatro personas para elaborar el Código $\mathrm{Civi}^{38}$. El representante del derecho de costumbres (droit coutumier) era Tronchet, presidente de la Corte de Casación, y Bigot de Préameneu; ambos habían sido abogados ante el parlamento de París; los representantes del derecho escrito fueron Portalis, un alto administrador oficial y un brillante orador y escritor, y Maleville, juez de la Corte de Casación. En cuatro meses estos comisionados produjeron el proyecto de Código Civil, promulgado el 21 de marzo de 1804. Este Código derogó el antiguo régimen (I'ancien droit), las costumbres, el derecho romano y

\footnotetext{
${ }^{35}$ SAvigny, De la vocación de nuestra época para la legislación y la ciencia del derecho (1814), en La Codificación, una controversia programática basada en las obras de THIBAUT y SAVIGNY, Traducción del alemán de Díaz García, José, Editorial Aguilar, Madrid, España, 1970, p. 61.

${ }^{36}$ Savigny, De la vocación, cit. nota n. 35, p. 69 y 75.

${ }^{37}$ MerRYMAn, John Henry, La Tradición Jurídica Romano-Canónica, Tercera Edición, Colección Brevarios del Fondo de Cultura Económica, № 218, Traducción de Eduardo L. Suárez, México, 2000, p. 62.

${ }^{38}$ Portalis, Jean Etienne Marie, Discurso Preliminar del Código Civil Francés, Colección Cuadernos Civitas, Editorial Civitas S.A., Madrid, España, 1997, p. 27.
} 
las ordenanzas reales en las materias que él trataba ${ }^{39}, y$, posteriormente, rigió en los territorios conquistados por Napoleón. Por supuesto, el Código Civil establecía importantes logros de la revolución como el derecho de todas las personas a tener propiedad privada, la completa abolición de las servidumbres feudales, la completa secularización del matrimonio, la prohibición de las sustituciones fideicomisarias son, en efecto, claros ejemplos de esto ${ }^{40}$. Pero las dificultades de armonizar el derecho de costumbres con el derecho escrito dejaron en claro que muchas de las instituciones que habían sobrevivido desde la destrucción del imperio romano debían ser mantenidas, para lo cual los comisionados tuvieron muy en cuenta el trabajo doctrinal de Pothier. Finalmente, la idea de que este Código Civil reemplazara en su totalidad el sistema anterior y no tuviera ningún contacto con la historia jurídica del territorio en el cual iba a ser aplicado tuvo que ser revaluada, luego de que se constatara que muchas de sus instituciones adoptaban claramente principios legales que habían regido por centurias en el continente europeo ${ }^{41}$, como por ejemplo, el muy célebre artículo 1134 que de acuerdo con la traducción oficial en español dice: "Los acuerdos legalmente formados tendrán fuerza legal entre quienes los hayan efectuado. Podrán ser revocados por mutuo consentimiento, o por las causas que autoriza la ley. Deberán ser ejecutados de buena $\mathrm{fe}^{\prime \prime} .{ }^{42}$

2. El BGB. Después de la derrota de Napoleón, las discusiones para mantener o no la vigencia de este código no se hicieron esperar. En Alemania, en particular, una escuela histórica del derecho, liderada por el muy bien conocido romanista Savigny consideraba que el derecho del pueblo alemán era el derecho del pueblo romano ${ }^{43}$ y no el Código Napoleón ${ }^{44}$. La idea de Savigny, preponderó y un grupo de pandectistas bajo la dirección de René Windscheid elaboró un Código Civil en 1896 que entró en vigor el 1 de enero de 1900, denominado el BGB. Las diferencias en la técnica legislativa de estos dos códigos, el francés de una parte y alemán del otro, consisten en que si para el primero debía el código enunciar grandes máximas abstractas a las cuales el comportamiento de la sociedad tuviera que adoptarse y, en consecuencia, debía utilizarse un lenguaje claro y práctico; para el BGB era necesario adoptar conceptos abstractos y muy refinados destinados

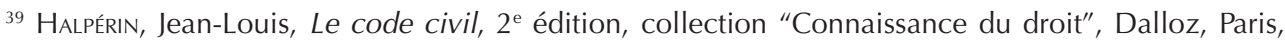
2003, p. 24.

${ }^{40}$ Losano, Los grandes, cit. nota n. 7, p. 57.

${ }^{41}$ ZweiGert, Konrad; KÖTz, Hein, An Introduction to Comparative Law, translated by Tony Weir, Oxford University Press, third edition, Oxford, New York, 1998, p. 86.

${ }^{42}$ Traducción al castellano disponible En: http://www.legifrance.fr. [Visitado el 15/06/2011]

${ }^{43}$ SAVIGNY, De la vocación, cit. nota n. 35, p. 48.

${ }^{44}$ Thibaut, Sobre la necesidad de un derecho civil general para Alemania". En La Codificación, cit. nota n. 35, p. 24. 
en general para los abogados y los profesores, esto es, los grandes conocedores del derecho, y organizados en una parte general seguida de dos partes especiales. Muchos de los países que habían adoptado el Código Napoleón, reemplazaron este código por el alemán de 1900, por ejemplo, Austria y Japón, para mencionar algunos. Otros hicieron nuevos códigos inspirados en este código alemán: el Código Suizo de las obligaciones de 1916 y el Código Civil italiano de 1942, conocido este como el último gran código de Europa. No obstante, en América Latina la influencia que tuvo el Código Napoleón en las nuevas Repúblicas que clamaron su independencia del yugo español fue preponderante.

3. El Código de Bello. Algunas de estas nuevas repúblicas adoptaron como nueva legislación el Código francés, caso de la República Dominicana, por ejemplo. Pero otros dejaron la tarea de crear estas nuevas leyes a ciertos sabios como don Andrés Bello y don Dalmavio Vélez Sársfield ${ }^{45}$. Nos referiremos en particular al Código de Bello, que ha regido en Colombia sin interrupción desde 1873 hasta la fecha. Para redactarlo, este humanista de origen venezolano ${ }^{46}$ trabajó desde 1831 hasta 1855 en su elaboración. Bello utilizó varias fuentes: El Derecho español, anteriormente referenciado, los Códigos civiles de Francia, Prusia, Luisiana, de las Dos Sicilias, de Holanda y el Proyecto de Goyena para España; y los comentarios de la doctrina francesa de principios del siglo XIX, tales como Troplong, Duvergier, Delvincour, Laurent, etc.; y para su aprobación, tres proyectos del Código Civil fueron publicados en un periódico llamado $E I$ Araucano desde 1841 hasta 1845, el primero, en 1847 el segundo; y en 1853 el tercero. Este último fue el promulgado como Ley de la República de Chile el 14 de diciembre de $1855^{47}$.

Ahora bien, tal como sucedió en Francia luego de la Revolución francesa, y en Alemania, liberada del Imperio de Napoleón, la ideología de la codificación que llegó a América Latina condujo a que el Código civil para Chile y Colombia fuera una obra conciliadora entre el espíritu tradicional, representado por la legislación española, y las corrientes de renovación de este espíritu francés de

\footnotetext{
${ }^{45}$ IzQuierdo, Florentino V., Vélez Sársfield: Vida y Obra Codificadora. Premio "Ministerio de Justicia de la Provincia de Córdoba - Año 2000", Academia Nacional de Derecho y Ciencias Sociales de Córdoba, Córdoba, República Argentina, 2000, p. 44.

${ }^{46}$ Don Andrés Bello no había estudiado leyes en su juventud, sino que estudió por su cuenta las Siete Partidas en lengua castellana y contaba con una gran erudición y talento en muchas ciencias: literatura, filosofía, gramática latina y castellana, astronomía e historia. Sin embargo, para emprender la ardua tarea de redactar el Código Civil, habiendo entrado ya en edad madura, emprendió los estudios de derecho.

47 Se conoció posteriormente los estudios y revisiones de Andrés Bello al Proyecto de 1853, en lo que se llama hoy "el proyecto inédito", el cual constituye un eslabón fundamental para la comprensión del proyecto de Código aprobado.
} 
principios del Siglo XIX ${ }^{48}$. Bien lo explica el profesor Rodríguez Piñeres: "Si en Chile mismo el Código no fue una obra autóctona, que es decir un fruto originario del mismo país, que hubiera dado forma metódica a la legislación que tenía -sino que en gran parte los fue de adaptación de legislaciones extranjeras, que robustecieron y vigorizaron al recio tronco de la española allí vigente-, en Colombia, no se hizo otra cosa que adoptar sencillamente la codificación chilena, con pequeñas modificaciones que, lejos de perfeccionarla, la desvirtuaron (...)" $)^{\prime \prime 4}$.

En consecuencia, el sistema de derecho continental se caracteriza por ser un sistema de derecho escrito que reposa en códigos en particular el Código Civil y cuyos principios fundamentales son similares debido a que provienen de las instituciones de Derecho Romano. A continuación se explicará la dinámica de estas leyes escritas y codificadas.

\section{La dinámica de las disposiciones del Sistema del Derecho Continental y LA INNECESARIA TRANSFORMACIÓN DEL DERECHO COLOMBIANO HACIA UN "DERECHO NUEVO"}

Los componentes del Sistema continental han creado las categorías que lo identifican de los otros sistemas. Ellas juegan un rol fundamental en Derecho comparado, toda vez que éstas constituyen el contenido del análisis del comparatista con el fin de descubrir los principios fundamentales y la finalidad de los derechos objeto de su análisis. Veremos así las categorías particulares del Sistema continental en primer lugar (A), para pasar a continuación a mostrar la forma como las reglas de este sistema se actualizan constantemente a través de la finalidad del Sistema (B).

\section{Las principales categorías del sistema de Derecho Continental}

La más grande de las categorías del Sistema de Derecho Continental es la división entre derecho público y derecho privado (1); dentro de éstas, además, pueden encontrarse otras, como son la de derecho sustancial y derecho procesal (2), derecho de obligaciones (3) o del consumidor (4).

\subsection{Derecho público y derecho privado}

Una de las características fundamentales del derecho de los países inscritos en el Sistema Continental es la división de sus reglas jurídicas entre Derecho

\footnotetext{
${ }^{48}$ Ibidem. En este sentido: Mayorga, Fernando, Pervivencia del Derecho Español durante el Siglo XIX y proceso de codificación civil en Colombia, En: Temas Jurídicos, № 2, Colegio Mayor de Nuestra Señora del Rosario, Bogotá, abril 1991, p. 20.

${ }^{49}$ Rodríguez, Curso, cit. nota. n. 31 ( $\left.N^{\circ} 21\right)$, p. 53.
} 
público y derecho privado. La base de esta distinción se encuentra en una sola idea: "las relaciones entre gobernantes y gobernados plantean problemas propios y apelan a una reglamentación diferente a la de las relaciones entre los particulares, toda vez que el interés general y los intereses particulares no pueden ser pesados sobre los platillos de una misma balanza" ${ }^{\prime 50}$. Por esta razón es que en estos países el derecho se divide en ramas. Así, dentro del derecho público se encuentran el derecho administrativo, el constitucional y el penal; en tanto que en el derecho privado se tiene al derecho civil, comercial, laboral, entre otros. No obstante, hay ramas en las que convergen reglas del derecho público y del derecho privado. Así, una gran influencia del derecho privado en el derecho público puede ser constatada en las reglas de contratación estatal y de responsabilidad del Estado; en tanto que el derecho público ha influido en materia laboral a través del régimen de la seguridad social, en el derecho civil bienes a través del derecho tributario; del derecho de contratos y obligaciones a través del derecho del consumidor, y del derecho comercial mediante el aseguramiento y control de la libre competencia; de hecho, un gran fenómeno que demuestra la convergencia entre estas dos categorías de derechos se encuentra en una tendencia jurisprudencial conocida como la "constitucionalización del derecho privado".

\subsection{Derecho sustancial y derecho procesal}

Se entiende por derecho sustancial aquel que confiere derechos a las personas, en tanto que por derecho procesal, al conjunto de reglas que rigen la competencia, los procesos sujetos a la decisión de los jueces. En consecuencia, las únicas reglas que son sujeto de una interpretación jurisprudencial a través del recurso extraordinario de casación, son las reglas sustanciales de derecho, las cuales se encuentran en los Códigos sustantivos, como el civil, el comercial, el laboral y penal. Por su parte, el derecho procesal ha sido definido como "la rama de la ciencia jurídica que estudia la naturaleza, el desenvolvimiento y la eficacia del conjunto de relaciones jurídicas denominado proceso civil" 51, y sus reglas se encuentran en los Códigos de procedimiento, como el Código de procedimiento civil o penal.

\subsection{Derecho de obligaciones}

Este derecho constituye una categoría fundamental en los sistemas de Derecho Continental o Romano-germánico; no siendo así en las familias de la

${ }^{50}$ DAVID, JaufFRet-SPINOSI, Les grands, cit. nota n. 2, p. 63.

${ }^{51}$ Couture, Eduardo J., Fundamentos del Derecho Procesal Civil, p. 3, Roque Depalma Editor, Buenos Aires, 1958. 
Common law, en el que el concepto mismo de obligación es completamente desconocido, debido a que los diversos procedimientos utilizados para conocer y sancionar las obligaciones les ha impedido abstraer esos hechos para crear una noción de obligación. De hecho, la palabra "obligation" denota, según su origen y objeto, las sanciones resultantes del ejercicio de la acción de assumsit, la de negligence, de conversion, de nuisance y de trespass, etc. en dicho sistema ${ }^{52}$. Por el contrario, la obligación para la familia romanista es un vínculo jurídico entre dos personas, en la que una, llamada deudor, por un hecho suyo o por mandato de la ley, tiene que dar, hacer o no hacer una cosa a favor de otra, denominada acreedor $^{53}$. La más remota definición de obligación se encuentra en el Digesto: "Obligatio est juris vinculum, quo necessitate adstringimur alicuius solvendae rei secundum nostrae civitatis iura ${ }^{54}$. El Derecho de obligaciones constituye el centro del Derecho Civil, razón por la cual ocupa una atención constante de los profesores, abogados y jueces. En él se estudian las circunstancias a las cuales la ley confiere el poder de crear vínculos jurídicos entre las personas, a las cuales se les da por nombre Fuentes de la obligación, así como su régimen, sus efectos y la manera como dichas obligaciones pueden ser transferidas o transmitidas a otro patrimonio, probarse, transformarse o extinguirse. Recientemente, el Derecho de Obligaciones ha sido objeto de grandes reformas en algunos países pertenecientes al Sistema Continental. Alemania, en el año 2002, cambió una buena parte de las disposiciones del B. G.B. en relación con la prescripción, los efectos de las obligaciones, la venta y el contrato de prestación de servicios. En Francia se estudia la posibilidad de actualizar las reglas del Código Napoleón en razón de las posiciones jurisprudenciales, que pujan por la consagración legislativa de instituciones tales como la revisión por imprevisión, la lesión y la buena fe en la etapa precontractual, entre otras. Para estos efectos, dos anteproyectos de reforma del Derecho de las Obligaciones han sido elaborados en estos últimos años ${ }^{55}$.

Finalmente, en Colombia, el Derecho Civil de las Obligaciones constituye la columna de la formación jurídica de todo abogado. Sus reglas se encuentran contenidas en el Libro Cuarto del Código Civil, aunque la definición de derecho de crédito es mostrada desde el Libro Segundo, cuando se la opone

${ }^{52}$ DaVID, JaufFret-SpINOSI, Les grands, cit. nota n. 2, № 63, p. 67. Ver también David, René, Les contrats en droit anglais, L.G.D.J., Paris, 1973, p. 57.

${ }^{53}$ Ver artículo 666 del Código Civil colombiano.

${ }^{54}$ Inst. 3, 13.

55 El Ante-proyecto de reforma en Derecho de las obligaciones y de la prescripción, presentado a Mr. Pascal Clément, Garde des Sceaux, Ministro de la Justicia el 22 de septiembre 2005 y el Proyecto realizado por un equipo bajo la dirección de François Terre: Ver al respecto, Mazeaud, Denis, "La reforme du droit francais des contrats: trois projets en concurrence", en Liber amicorum Christian Larroumet, textos reunidos por Sarah Bros y Blandine Mallet-Bricout, Económica, Paris, 2010, p. 329 y ss. 
a la de derecho real (artículos 665 y 666 del Código Civil). Esta disciplina no ha tenido modificación alguna desde la adopción del Código Civil Chileno en 1887, aunque algunos consideran que los aspectos que quedaron en silencio en este Código fueron luego objeto de regulación por el Código de Comercio expedido en 1971. Estos aspectos se refieren particularmente a la incorporación del deber de buena fe en la etapa precontractual, a la clara determinación de la noción de contrato, a la introducción del mecanismo de formación del consentimiento por medio de la oferta y la aceptación, a la incorporación dentro de la legislación colombiana de la revisión por imprevisión y de dos nuevas fuentes de obligaciones, como son el enriquecimiento sin causa y el abuso del derecho ${ }^{56}$.

\subsection{Derecho del consumidor}

Se trata de una nueva rama del derecho en todos los países de tradición continental. Su origen se encuentra en la iniciativa legal o jurisprudencial de proteger al consumidor, considerado como la parte débil del contrato de venta. En Europa han crecido en gran número las Directivas Europeas, en orden a dotar a los países miembros de la Unión de unas reglas uniformes de protección al consumidor. En Colombia, la protección al consumidor tuvo su origen en una iniciativa gubernamental que trascendió a la legislación. En efecto, bajo las reglas de la anterior Constitución (numeral 12 del artículo 76), promulgada en 1886 y reemplazada en 1991, el Presidente de la República podía recibir del Congreso autorización para expedir Decretos con fuerza de Ley, durante el término que le fuera concedido para tales efectos, lo cual ocurrió en materia de distribución de Bienes y Servicios para la Defensa del Consumidor. De allí se estableció entre nosotros el Decreto 3466 de 1982, o, como se le conoce en la actualidad, el Estatuto de Protección al Consumidor. Este Decreto está destinado a regular los efectos que del incumplimiento imperfecto de una obligación se derivan para un consumidor, esto es, para la "persona natural o jurídica que contrata la adquisición, utilización o disfrute de un bien o la prestación de un servicio determinado, para la satisfacción de una o más necesidades". La imperfección de dicho cumplimiento resulta de una falta en la idoneidad o en la calidad del objeto de la obligación contratada, idoneidad y calidad del objeto que se compara en relación con aquellas que fueran previa-

\footnotetext{
${ }^{56}$ En este sentido, ver: Escobar SAnin, Gabriel, Negocios civiles y comerciales (II), Teoría general de los contratos, $1^{\text {a }}$ edición, Biblioteca Jurídica DIKE, Bogotá, 1994, № 800, p. 413; URIBE-Holguín, Ricardo, De las obligaciones y de los contratos en general, Editorial Temis, Bogotá, 1982, № 2, página 185; TAPIAS Rocha, Hernando, "La unidad del derecho privado colombiano", en PICASSO, Sebastián; MANTILLA Espinosa, Fabricio; Martínez-Cárdenas, Betty (Coords.), Introducción al Derecho, Editorial Universidad del Rosario, en prensa.
} 
mente determinadas mediante su registro por parte del productor o proveedor, ante una entidad gubernamental, en general, la Superintendencia de Industria y Comercio. Dicho registro es de carácter público (artículo $4^{\circ}$ ), y mediante él, el productor o proveedor establece la regla de conducta que debe seguir para el cumplimiento perfecto de la obligación que deriva del contrato celebrado con el consumidor. Por esta razón, el artículo $8^{\circ}$ del Decreto establece que: "El registro de calidad e idoneidad constituye el documento auténtico proveniente del productor de un bien o servicio, con base en el cual se podrá establecer la responsabilidad por la calidad e idoneidad del bien o servicio, por la garantía mínima presunta del productor y por las marcas, leyendas y la propaganda comercial de los bienes y servicios".

En la actualidad, los problemas derivados del consumo de bienes y servicios serán objeto de un Nuevo estatuto de protección al consumidor que, entre otros cambios, amplía la noción de Consumidor, para armonizarla con la contenida en la Directiva de la Unión Europea del 11 de mayo de 2005 ${ }^{57}$, en el sentido de identificar al Consumidor con el destinatario final del producto o servicio; introduce en Colombia las hipótesis de responsabilidad por producto defectuoso y responsabilidad de mercado; establece un catálogo de cláusulas abusivas, y promueve la interpretación pro consumatore del contrato. De igual forma, establece que los litigios en esta materia seguirán siendo solucionados directamente por las partes a través de una conciliación, o ante la Superintendencia de Industria y Comercio, dadas las facultades jurisdiccionales que se le atribuyeron con la Ley 446 de 1998; así como ante la jurisdicción ordinaria.

Vistas así las principales categorías que identifican al Derecho colombiano con las compartidas por los demás derechos pertenecientes al Sistema continental, se mostrará a continuación cómo la finalidad que tienen dichos sistemas Ileva a que sus reglas sean constantemente actualizadas al momento de ser aplicadas por los jueces, lo que haría innecesaria la mutación hacia un "nuevo derecho".

\section{Finalidad de las reglas en el sistema de Derecho Continental}

La preocupación principal del Sistema de Derecho Continental es la determinación de la regla que debe ser retenida como regla de derecho, esto es, como Ley. Las reglas colombianas comparten esta misma preocupación. Por ello tienen una técnica legislativa determinada (1) y un método de interpretación que permite la actualización constate de sus disposiciones (2).

57 Se entiende en esta Directiva que el consumidor es la "personne agissant à des fins qui pour l'essentiel n'entrent pas dans le cadre de l'activité professionnelle": PICOD, Yves; Davo, Hélène, Droit de la consommation, $2^{\mathrm{e}}$ édition, Dalloz, Paris, 2010, p. 23. 
1. La técnica legislativa del Sistema de Derecho Continental. "La técnica legislativa es un término que tiene por objeto describir una escena de la actividad del legislador: la redacción y la forma de la elaboración de la ley"58. Un ejemplo de diferencia de la técnica legislativa utilizada por el Sistema Continental en relación con la técnica de otros sistemas, surge de la noción de contrato. En efecto, la comparación de sistemas permite ver que si bien el contrato no es objeto de definición alguna en la Common law, razón por la cual su contenido se ha deducido directamente de las prácticas comerciales (a), en el Sistema continental tanto los Códigos civiles, como los Códigos comerciales se ocupan de ella (b).

a) El contrato en la Common law. En el Derecho Inglés, la noción de contrato se desarrolló como consecuencia del comercio y constituye una categoría autónoma mucho más marcada que en el sistema continental ${ }^{59}$. En efecto, desde el siglo XV, las Cortes Reales o Cortes de la Common law, recibieron acciones de naturaleza contractual, pero ellas no podían hacer que fueran ejecutados sino los acuerdos formales, que constaran por escrito y cumplieran con ciertas solemnidades, como el ser autenticados a través de un sello de cera. Fue sólo hacia el siglo XVII que estos tribunales de la Common law admitieron recursos en caso de ruptura de una simple promesa oral de ejecutar un acto. La rigidez de estos tribunales reales, marcada en particular por las estrictas exigencias formales, motivó a los abogados a buscar otras formas de obtener justicia. En ello, la Cancillería (Court of Chancery), tuvo un papel determinante. Esta Corte apareció en el siglo XIV como un órgano judicial y desarrolló otro principios distintos y paralelos a los desarrollados por las Cortes de la Common law. Por esta razón, en Inglaterra se desarrollaron dos sistemas judiciales diferentes, los de la Common law y los de la Cancillería; en los primeros, los jueces aplicaban el derecho común del Reino, en tanto que en el segundo, se aplicaban los principios de "equity"60. Esta división judicial sobrevivió hasta el Siglo XIX, cuando fueron fusionados ambos sistemas en uno solo. Los Estados Unidos heredaron este sistema jurídico de Inglaterra, trayendo consigo el germen para el desarrollo del derecho de contratos. Allí, la fuente principal continúa siendo la Common law, aun cuando exista un Código Comercial Uniforme (Uniform Commercial Code), que consiste en un simple esfuerzo de reglamentar las variaciones en materia de contratos comerciales entre los Estados.

Es así como de esta evolución se desarrolló el Derecho de contratos en la Common law. Evolución que se hizo por etapas. En el principio, para acceder

\footnotetext{
${ }^{58}$ LASSERRE-KIESOW, Valérie, La technique législative, étude sur les codes civils français et allemand, préface Michel Pédamon, L.G.D.J., Paris, 2002, p. 19.

${ }^{59}$ DaVID, Les contrats, cit. nota. N 52 ( $\left.\mathrm{N}^{\circ} 33\right)$, p. 57.

${ }^{60}$ Losano, Los grandes, cit. nota n. 7, p. 171.
} 
a la obtención de justicia en relación con un contrato, debía tenerse un "writ", del cual existían sólo tres categorías: El "debt", bajo el cual se reclamaba una suma de dinero cuyo monto era determinado. Dicha deuda estaba fundada sobre una idea de propiedad, ya que el demandante reclamaba el dinero que había confiado al demandado; el "convenant", que es la acción que más se aproximaba a una "acción contractual", pero sólo abarcaba los problemas inmobiliarios que dejaban suponer que se hacían de manera formal. Con el tiempo, esta acción perdió vigencia. Por último, el "trepass", consistente en la reparación de un daño causado por el demandado a la persona o a un bien del demandante. Se trataba de una acción que tuvo mucho éxito, que apareció hacia el siglo XIII y trajo una concepción distinta sobre el proceso, ya que, con esta acción, el Juez estatuye de acuerdo con las pruebas allegadas por las partes. A partir de esta acción, se desarrolló el Derecho de contratos en este Sistema ${ }^{61}$.

La segunda etapa en esta evolución es la acción de "assumpsit", ya que los "writ" fueron abolidos en 1852. Esta nueva acción se podía ejercer por dos causas, in consimilicasu, esto es, a través de un razonamiento por analogía; y por suporcasum, es decir, de acuerdo con la especie a decidirse. La acción de "assumpsit" se ejerció de manera progresiva en casos de una culpa "positiva", dada por una mala inejecución; y por una actitud pasiva. El nombre de "assumsit" viene del hecho que el demandado adquirió un compromiso que no respetó, siguiendo en esto las tendencias provenientes del sistema romano-germánico (Pothier y Savigny), según la cual, el contrato era un acuerdo de voluntades. Pero no era suficiente para una Corte real que se ejerciera una acción semejante a partir de la adquisición del compromiso, era necesario que la inejecución del mismo se realizara luego de que se hubiera pagado la contrapartida del mismo, a lo cual se le denominó "consideration". Por ello, ante la ausencia de "consideration", no había contrato. En tercer lugar, la evolución muestra hoy en día que el derecho de contratos del sistema anglo-americano no tiene por única fuente a la jurisprudencia, sino que se han creado numerosas leyes y "statutes" que lo contienen.

Siendo explicado esto, se verá a continuación las principales diferencias del contrato en el Derecho colombiano, que lo hacen, sin duda alguna, pertenecer al Sistema Continental.

b) El contrato en el Derecho Colombiano: reglas propias del Sistema Continental. A diferencia de los contratos en la Common law, la moral cristiana no se interesa en el comercio. En efecto, en Colombia, tal como sucedió en el continente europeo, las nociones de contrato que se conocen han sido enor-

${ }^{61}$ Por fuera de estas tres acciones, había otros medios de sancionar una culpa contractual ante las jurisdicciones eclesiásticas, que aplicaban únicamente sanciones morales. 
memente influenciadas por el Derecho Romano ${ }^{62}$ y luego, hacia el siglo XVI, por el derecho canónico.

Una primera concepción del contrato, apoyada sobre los principios filosóficos de libertad individual y autonomía de la persona, explica al contrato como una especie de convención, ya que se trata de un acuerdo de voluntades del que nacen obligaciones ${ }^{63}$, según se lee del 1101 del Código Civil francés. A esta concepción se la denomina "voluntarista"64.

Para otros, los países que se ajustaron aún más a los principios del Derecho Romano, el contrato es un término abstracto que en la actualidad es utilizado para satisfacer necesidades económicas a través de la creación, modificación y extinción de obligaciones. Noción reconocida por el artículo 1495 del Código Civil colombiano ${ }^{65}$ y reforzada por el artículo 864 del Código de Comercio colombiano, que se une a la del parágrafo 305 del Código Civil alemán (BGB), y a la del artículo 1321 del actual Código Civil italiano.

Para poder formarse, el contrato en los Sistemas continentales debe cumplir con cuatro condiciones, como que los contratantes sean capaces, otorguen un consentimiento libre de vicios y que dicho consentimiento sea motivado por una causa lícita y tenga un objeto lícito (artículo 1502 del Código Civil colombiano). El hecho de que la mera liberalidad pueda constituir una causa, explica que en estos países de tradición continental, a diferencia de los de Common law, se conozcan los contratos a título gratuito, esto es, que no sea necesaria la contraprestación para que haya contrato ${ }^{66}$. Una vez formado, del contrato se deducen tres efectos principales, como son el obligatorio, el relativo y el inmutable tal como se ha establecido en los artículos 1602 del Código Civil colombiano, 1545 del Código Civil chileno, 1134 del Código Civil francés, 311 del BGB, y 1372 y 1373 del Código Civil italiano, para citar los textos más importantes.

Del efecto obligatorio se tiene, en breve, que del contrato surgen relaciones obligatorias que han de ser cumplidas de acuerdo con los términos del mismo contrato o con los términos deducidos de la aplicación de la buena fe

\footnotetext{
${ }^{62}$ Ourliac, Paul; Gazzaniga, Jean-Louis, Histoire du droit privé français de l'An mil au Code civil, Albin Michel, Paris, 1985, p. 134

${ }^{63}$ Tesis defendida por la doctrina clásica francesa a partir de las obras de Domat, Pothier y Pufendorf, por ejemplo.

${ }^{64}$ LaITHIER, Yves-Marie, Droit Comparé, collection Cours de Dalloz, Paris, 2009, p. 95.

${ }^{65}$ Rocha Alvira, Antonio; Martínez-Cárdenas, Betty, Lecciones de Obligaciones de Antonio Rocha Alvira, Serie Memoria Viva, Editorial Universidad del Rosario, Bogotá, 2009, p. 23. Disponible también en: http://books.google.com/books?id=swLbAGAX6OsC\&printsec=frontcover\&dq=Betty+Mercedes+Mar $\mathrm{t} \% \mathrm{C} 3 \% \mathrm{ADnez}+\mathrm{C} \% \mathrm{C} 3 \% \mathrm{~A} 1 \mathrm{rdenas} \&$ source=bl\&ots=ZNDUn1TY6\&sig=HhAGMD8eSYioFOCNJrdHN 2AEhZY\&hl=es\&ei=h55dTamhE8mCgAet_3aDA\&sa $=X \& o i=b o o k \_r e s u l t \& c t=r e s u l t \& r e s n u m=7 \& v e d=$ 0CD0Q6AEwBg\# $\mathrm{v}=$ onepage \&q\& $\mathrm{f}=\mathrm{false}$ [Visitado el 03/02/2011].
}

${ }^{66}$ LaITHIER, Droit, cit. nota n. 34 (№ 41), p. 95. 
en la ejecución del mismo (artículo 1603 del Código Civil colombiano, 1546 del Código Civil chileno, Inciso tercero del artículo 1134, y artículo 1135 del Código Civil francés, 157 del BGB y 1375 del Código Civil italiano). Del efecto relativo, que los que se encuentran sujetos al cumplimiento de las relaciones jurídicas derivadas del contrato, son las partes, esto es, quienes consintieron; de allí que, en principio, frente a terceros el contrato no produzca efecto alguno, salvo cuando se trate de un "tercero relativo" que por virtud de una hipótesis de hecho, como la muerte, o de un modo de transferencia de derechos de crédito (cesión de contrato o la promesa en beneficio de un tercero, por ejemplo) un tercero se convierte en causa-habiente del contratante, sea a título universal o a título particular, y en consecuencia, debe ejecutar el contrato o se beneficiará del mismo como si hubiera consentido, o, si se tratare de un tercero "absoluto", quien podrá oponerse siempre al contrato, para no tener que ejecutarlo u oponerlo en su beneficio, ya que las partes en virtud de dicho contrato deben cumplir ciertas obligaciones que a él le interesan (caso del llamamiento en garantía, por ejemplo). Por último, la inmutabilidad del contrato hace referencia a que éste no debe ser modificado, sino por el mutuo acuerdo de las partes o por las disposiciones legales, hipótesis que denota la gran importancia que tiene para este sistema la aplicación de la justicia distributiva entre los contratantes, con acciones tales como la revisión por imprevisión, por ejemplo.

En consecuencia, aunque el contrato sea un instrumento de circulación de la riqueza utilizado en el mundo entero, los requisitos para formarlos y sus efectos dependen en gran medida del sistema de derecho en el que se vayan a ejecutar sus obligaciones. En materia de Derecho internacional privado, los problemas de diferencia de sistemas están a la orden del día, y han sido tan importantes que se ha requerido la creación de varias convenciones internacionales para poder determinar la ley aplicable al contrato en caso de incumplimiento o de problemas de interpretación con sus disposiciones ${ }^{67}$.

Ahora bien, no sólo el Sistema Continental se distingue por la técnica legislativa, sino también, por los métodos de interpretación de la misma que se han desarrollado en su seno.

2. Los métodos de interpretación de la regla jurídica. En tanto que la elaboración de la regla de derecho es la preocupación constante del Sistema Continental, ya que los derechos de esta familia no se elaboran a partir de las teorías de la doctrina ni de los jueces, sino del legislador mismo, veremos primero que estas reglas corresponden a una abstracción de los hechos (a) y a la formulación de una regla escrita de derecho (b).

${ }^{67}$ Ver Ley 518 de 1999, mediante la cual se incorpora en la legislación colombiana la Convención de Viena del 11 de abril de 1980 sobre compra-venta internacional de mercaderías. 
a) La abstracción de los hechos. El conocimiento que tiene toda persona de sus derechos, con independencia de la manera como éstos son aplicados por los jueces, otorga una gran seguridad jurídica. De allí que los interesados puedan regular sus relaciones jurídicas con independencia de los jueces, y que sólo se acuda a éstos en caso de conflicto o de necesidad de constituir un derecho. Además, la regla escrita permite un claro reflejo de la separación de poderes públicos: el Legislativo escribe la ley, el Ejecutivo la sanciona y el Judicial la aplica. Toda regla jurídica en materia civil está compuesta de dos partes: una hipótesis de hecho y una consecuencia jurídica. El artículo cuarto del Código Civil dispone claramente que dicha consecuencia puede ser un mandato, un permiso, una prohibición o un castigo. De allí que al momento de ejercer un derecho a través de una demanda, el capítulo de hechos de la misma corresponda a la hipótesis de hecho prevista por el artículo cuya sanción se pedirá posteriormente en el capítulo de pretensiones. De igual forma, el artículo cuya aplicación se pretende, hará parte de los fundamentos de derecho de la demanda y, en el capítulo de pruebas, la práctica de aquéllas conducentes a la prueba de la hipótesis de hecho es la que deberá ser solicitada, conforme lo prevé el artículo 177 del Código de Procedimiento Civil colombiano: "Incumbe a las partes probar el supuesto de hecho de las normas que consagran el efecto jurídico que ellas persiguen".

En consecuencia, es la abstracción de los hechos la que permite razonar en términos jurídicos con el fin de obtener la sanción de un derecho ${ }^{68}$. Para determinar la interpretación de la regla jurídica y dotarla de vida al momento de aplicarla se han desarrollado en los países de Sistema continental varios sistemas, como el recurso extraordinario de casación o de revisión. En otras palabras, la regla se convierte así en "Derecho Viviente"69.

b) La formulación de una regla escrita de derecho: el recurso de casación. En efecto, en los países de tradición continental, el máximo órgano judicial es el encargado de unificar la interpretación del derecho. Esta unificación de la interpretación del derecho, que es lo que constituye la jurisprudencia, es fundamental para lograr, de un lado, aclarar el sentido de un texto de derecho sustancial, y del otro, la actualización de la regla de derecho, a través de la integración del mismo, esto es, Ilenando las lagunas a través de la aplicación del texto legal a hipótesis de hecho originalmente no previstas por el legislador ${ }^{70}$. En

\footnotetext{
${ }^{68}$ Rodrícuez, Jorge L., Lógica de los Sistemas Jurídicos, Colección "El Derecho y la Justicia", Centro de Estudios Políticos y Constitucionales, Madrid, 2002, p. 22.

${ }^{69}$ Losano, Los grandes, cit. nota n. 7, pp. 328 y ss.

70 RodríGuez, César, La decisión Judicial: El Debate HART - DWORKIN, Colección Nuevo Pensamiento Jurídico. $6^{a}$ Reimpresión. Siglo del Hombre Editores, Universidad de los Andes, Bogotá, 2008, p. 137.
} 
Colombia, esa es la razón por la que el artículo 365 del Código de Procedimiento Civil establece que "El recurso de casación tiene por fin primordial unificar la jurisprudencia nacional y proveer a la realización del derecho objetivo en los respectivos procesos; además procura reparar los agravios inferidos a las partes por la sentencia recurrida". De allí que esta tarea se le ha reservado a la Corte Suprema de Justicia, desde 1886 ${ }^{71}$; en Francia, a la Cour de Cassation, creada por la Asamblea Constituyente en 1790, y en Alemania, unificada en la época de Bismarck, la revisión es conocida por la Corte Suprema de Justicia.

La diferencia fundamental entre la casación y la revisión es que en la primera no se le permite al juez conocer el litigio, en tanto que la segunda constituye una verdadera tercera instancia. En la casación, en efecto, no se le permite al juez "declarar el derecho con la misma libertad que corresponde al juez de instancia puesto que ella se encuentra sometida a los medios o motivos alegados"72. En efecto, la casación tiene por principal objetivo encontrar los fundamentos jurídicos que quiebren el razonamiento del juez de segunda instancia a través de varias causas, o "causales", como las nombra el artículo 368 del Código de Procedimiento Civil ${ }^{73}$. Por su parte, con la institución alemana de la "revisión", la Suprema Corte puede anular una decisión en razón de una interpretación incorrecta, instruir a los jueces inferiores sobre la que sería correcta y "revisar", en consecuencia, la decisión incorrecta ${ }^{74}$.

Nótese, sin embargo, que a estas Cortes no se les atribuyó la creación del derecho, sino la de unificar la interpretación del mismo; ya que bien lo dispone

\footnotetext{
${ }^{71}$ Así ha sido desde 1886, según se lee en el numeral 10 de la Sección Segunda del artículo 21 de la Ley 61 de ese mismo año, ley que provisionalmente estableció la organización y las atribuciones del Poder Judicial. Posteriormente, el artículo $1^{\circ}$ de la Ley 169 de 1896 de la República de Colombia aclara esas atribuciones en relación con el recurso de casación: "Con el fin principal de uniformar la jurisprudencia, y con el de enmendar los agravios inferidos a las partes, se concede el recurso de casación para ante la Corte Suprema de Justicia contra las sentencias definitivas de segunda instancia dictadas por los Tribunales Superiores de Distrito Judicial..."; esta particular atribución fue posteriormente reconocida por el artículo 235 de la Constitución Política de 1991.

72 Murcia Ballen, Humberto, Recurso de casación civil, 4ª Edición Actualizada, Ediciones Jurídicas Gustavo Ibáñez, Bogotá, 1996, p. 50.

73 Artículo 368 del Código de Procedimiento Civil "1. Ser la sentencia violatoria de una norma de derecho sustancial. La violación de norma de derecho sustancial, puede ocurrir también como consecuencia de error de derecho por violación de una norma probatoria, o por error de hecho manifiesto en la apreciación de la demanda, de su contestación o de determinada prueba"; "2. No estar la sentencia en consonancia con los hechos, con las pretensiones de la demanda, o con las excepciones propuestas por el demandado o que el juez ha debido reconocer de oficio"; "3. Contener la sentencia en su parte resolutiva declaraciones o disposiciones contradictorias"; "4. Contener la sentencia decisiones que hagan más gravosa la situación de la parte que apeló o la de aquélla para cuya protección se surtió la consulta siempre que la otra no haya apelado ni adherido a la apelación, salvo lo dispuesto en el inciso final del artículo 357", y, "5. Haberse incurrido en alguna de las causales de nulidad consagradas en el artículo 140, siempre que no se hubiere saneado".

${ }^{74}$ Merryman, La Tradición, cit. nota n. 37, p. 85.
} 
el artículo 17 del Código Civil colombiano, "Las sentencias judiciales no tienen fuerza obligatoria, sino respecto de las causas en que fueron pronunciadas. Es, por tanto, prohibido a los jueces proveer en los negocios de su competencia por vía de disposición general o reglamentaria". Regla que se encuentra también en el artículo $5^{\circ}$ del Código Civil francés. Y la razón de ello es que "...la ley estatuye para todos; considera a los hombres en masa, nunca como particulares; no debe ocuparse de los hechos individuales ni de los litigios que separan a los ciudadanos. Si fuera de otro modo, habría que hacer nuevas leyes diariamente: su multitud ahogaría su dignidad y perjudicaría su cumplimiento. El jurista quedaría sin funciones, y el legislador, arrastrado por los detalles, pronto sería un simple jurista, pronto no sería más que un jurisconsulto. Los intereses particulares sitiarían el poder legislativo; le apartarían, a cada instante, del interés general de la sociedad"75.

Siguiendo estos parámetros, Colombia luego de discutir vivamente el rol de la jurisprudencia como fuente de derecho, le dio este poder sólo de manera secundaria, y bajo unas condiciones especiales: "Tres decisiones dadas por la Corte Suprema como Tribunal de Casación sobe un mismo punto de derecho, constituyen doctrina probable, y los jueces podrán aplicarla en casos análogos, lo cual no obsta para que la Corte varíe la doctrina en caso de que juzgue erróneas las decisiones anteriores". (Artículo $4^{\circ}$ de la Ley 169 de 1896). Todo lo cual sigue siendo confirmado, muy a pesar de algunos, por el artículo 230 de la Constitución Nacional que establece claramente que "Los jueces, en sus providencias, sólo están sometidos al imperio de la ley... La equidad, la jurisprudencia, los principios generales del derecho y la doctrina son criterios auxiliares de la actividad judicial".

\section{CONCLUSIÓN}

La concepción de "derecho nuevo" que defiende una parte de la doctrina colombiana no tiene en cuenta para su desarrollo sino las reglas que la Constitución previó para la interpretación de los fallos proferidos por la Corte Constitucional. Estas "reglas" no tienen en consideración la técnica legislativa y los métodos de interpretación de todo el conjunto que conforma el Derecho colombiano.

Por el contrario, la técnica legislativa y la casación como medio para interpretar le ley por el juez constituyen una herramienta suficiente para actualizar las reglas de derecho y evitar así la proliferación de leyes especiales.

Finalmente, el futuro del Sistema continental, particularmente en Colombia, no depende de la tendencia que en los últimos años se haya tenido hacia la

${ }^{75}$ Portalis, Discurso, cit. nota n. 38, p. 44. 
"constitucionalización" de las distintas ramas del Derecho que lo conforman, toda vez que por este nombre se reconoce en la actualidad un fenómeno que ha pervivido con el Sistema desde el principio, y que no consiste sino en la confirmación del mismo: la aplicación de una regla escrita de derecho.

\section{BiBLIOGRAFÍA}

Chomskr, Noam, La quinta libertad, La intervención de los Estados Unidos en América Central y la lucha por la paz, Traducción castellana de Castells, Carme, Editorial Crítica, colección Biblioteca de Bolsillo, Barcelona, 2003.

Couture, Eduardo J., Fundamentos del Derecho Procesal Civil, Roque Depalma Editor, Buenos Aires, 1958.

DAVID, René, Les contrats en droit anglais, L.G.D.J., Paris, 1973.

DAVID, René, JaufFret-SpINOSI, Camille, Les grands systèmes du droit contempo-

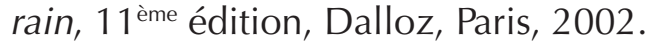

Escobar Sanin, Gabriel, Negocios civiles y comerciales (II), Teoría general de los contratos, $1^{\text {a }}$ edición, Biblioteca Jurídica DIKE, Bogotá, 1994.

Halpérin, Jean-Louis, Le code civil, 2e édition, collection "Connaissance du droit", Dalloz, Paris, 2003.

IzQUierdo, Florentino V., Vélez Sársfield:Vida y Obra Codificadora, Premio "Ministerio de Justicia de la Provincia de Córdoba - Año 2000", Academia Nacional de Derecho y Ciencias Sociales de Córdoba, Córdoba, República Argentina, 2000.

Kunkel, Wolfgang, Historia del Derecho Romano, Ariel Derecho, Madrid, 1996.

Laithier, Yves-Marie, Droit Comparé, collection Cours de Dalloz, Paris.

LASSERRE-Kiesow, Valérie, La technique législative, étude sur les codes civils français et allemand, préface Michel Pédamon, L.G.D.J., Paris, 2002.

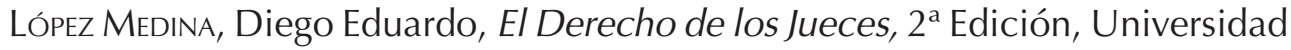
de los Andes y Legis, Bogotá, 2008.

Losano, Mario G., Los Grandes Sistemas Jurídicos, Introducción al Derecho Europeo y Extranjero, versión castellana de Ruiz Miguel, Alfonso, Editorial Debate S.A., Madrid, 1993.

Mayorga García, Fernando, Estudios de Derecho Indiano, Colección Textos de Jurisprudencia, Centro Editorial Universidad del Rosario, Bogotá, 2003.

, Pervivencia del Derecho Español durante el Siglo XIX y proceso de codificación civil en Colombia, en Temas Jurídicos, № 2, Colegio Mayor de Nuestra Señora del Rosario, Bogotá, abril 1991.

MAzeAud, Denis, "La reforme du droit français des contrats: trois projets en concurrence", En: Liber amicorum Christian Larroumet, textos reunidos por Sarah Bros y Blandine Mallet-Bricout, Economica, Paris, 2010. 
Merryman, John Henry, La Tradición Jurídica Romano-Canónica, $3^{\circ}$ Edición, Colección Brevarios del Fondo de Cultura Económica, No. 218, Traducción de Eduardo L. Suárez, México, 2000.

Merryman, John Henry; Pérez-Perdomo, Rogelio, The Civil Law Tradition, An Introduction to the Legal Systems of Europe and Latin America, third edition, Stanford University Press, Stanford, California, 2007.

Milııot, Louis et Blanc François-Paul, Introduction à l'étude du droit musulman, Dalloz, Paris, 2001.

MurCia Ballen, Humberto, Recurso de casación civil, Ediciones Jurídicas Gustavo Ibáñez, 4ª Edición Actualizada, Bogotá, 1996.

Ost CAPDequi, José María, Manual de Historia de Derecho Español en las Indias, y del Derecho propiamente indiano, Editorial Losada S.A., Buenos Aires, 1945.

Ourliac, Paul Et Gazzaniga, Jean-Louis, Histoire du droit privé français de l'An mil au Code civil, Albin Michel, Paris, 1985.

Portalis, Jean Etienne Marie, Discurso Preliminar del Código Civil Francés. Colección Cuadernos Civitas, Editorial Civitas S.A., Madrid, España, 1997.

PICOD, Yves; Davo, Hélène, Droit de la consommation, $2^{\mathrm{e}}$ édition, Dalloz, Paris, 2010.

Rocha Alvira, Antonio; Martínez-CÁrdenas, Betty, Lecciones de Obligaciones de Antonio Rocha Alvira, Serie Memoria Viva, Editorial Universidad del Rosario, Bogotá, 2009.

Rodrícuez, César. La decisión Judicial: El Debate Hart-Dworkin, Colección Nuevo Pensamiento Jurídico, 6 a Reimpresión. Siglo del Hombre Editores, Universidad de los Andes, Bogotá, 2008.

RodríGuez, Jorge L., Lógica de los Sistemas Jurídicos, Colección "El Derecho y la Justicia", Centro de Estudios Políticos y Constitucionales, Madrid, 2002.

Rodríguez Piñeres, Eduardo, Curso Elemental de Derecho Civil Colombiano, Segunda edición, Librería Americana, Bogotá, 1923.

SAVIGNY, De la vocación de nuestra época para la legislación y la ciencia del derecho (1814). En: La Codificación, una controversia programática basada en las obras de Thibaut y Savigny. Traducción del alemán de Díaz García, José, Editorial Aguilar, Madrid, España, 1970.

TAPIAS ROCHA, Hernando, "La unidad del derecho privado colombiano", en PICASso, Sebastián; Mantilla Espinosa, Fabricio, Martínez-CÁrdenas, Betty (Coords.), Introducción al Derecho, Editorial Universidad del Rosario, en prensa.

TerRé, François, Introduction générale au droit, 8e édition, Dalloz, Paris, 2010.

Uribe-Holguín, Ricardo, De las obligaciones y de los contratos en general, Editorial Temis, Bogotá, 1982. 
ZweIGeRT, Konrad and Kötz, Hein, An Introduction to Comparative Law, Vol. I., North-Holland Publishing company, Great Britain, 1977. An Introduction to Comparative Law, translated by Tony Weir, Oxford University Press, third edition, Oxford, New York, 1998.

Watson, Alan, Legal Transplants, an approach to comparative law, Second edition, The University of Georgia Press, Athens and London, 1993. 
